\title{
Teleophthalmology: improving patient outcomes?
}

This article was published in the following Dove Press journal:

Clinical Ophthalmology

10 February 2016

Number of times this article has been viewed

\author{
Omana Kesary Sreelatha' \\ Sathyamangalam \\ VenkataSubbu Ramesh ${ }^{2}$ \\ 'Ophthalmology Department, Sultan \\ Qaboos University Hospital, Muscat, \\ Oman; ${ }^{2}$ Department of Optometry, \\ School of Allied Health Sciences, \\ Manipal University, Manipal, India
}

Correspondence: Sathyamangalam VenkataSubbu Ramesh

Department of Optometry, School of Allied Health Sciences, Manipal University, Manipal 576104, India Tel +9l 886 I330950

Email ramesh.sve@manipal.edu
Abstract: Teleophthalmology is gaining importance as an effective eye care delivery modality worldwide. In many developing countries, teleophthalmology is being utilized to provide quality eye care to the underserved urban population and the unserved remote rural population. Over the years, technological innovations have led to improvement in evidence and teleophthalmology has evolved from a research tool to a clinical tool. The majority of the current teleophthalmology services concentrate on patient screening and appropriate referral to experts. Specialty care using teleophthalmology services for the pediatric group includes screening as well as providing timely care for retinopathy of prematurity (ROP). Among geriatric eye diseases, specialty teleophthalmology care is focused toward screening and referral for diabetic retinopathy (DR), glaucoma, age-related macular degeneration (ARMD), and other sight-threatening conditions. Comprehensive vision screening and refractive error services are generally covered as part of most of the teleophthalmology methods. Over the past decades, outcome assessment of health care system includes patients' assessments on their health, care, and services they receive. Outcomes, by and large, remain the ultimate validators of the effectiveness and quality of medical care. Teleophthalmology produces the same desired clinical outcome as the traditional system. Remote portals allow specialists to provide care over a larger region, thereby improving health outcomes and increasing accessibility of specialty care to a larger population. A high satisfaction level and acceptance is reported in the majority of the studies because of increased accessibility and reduced traveling cost and time. Considering the improved quality of patient care and patient satisfaction reported for these telemedicine services, this review explores how teleophthalmology helps to improve patient outcomes.

Keywords: teleophthalmology, patient satisfaction, patient outcomes, tele-ROP, tele-diabetic retinopathy, teleglaucoma

\section{Introduction}

The trends in increasing spread of technology worldwide, mobile broadband use, use of social media, and increasing e-commerce have allowed health care fraternities to incorporate information technology for eye care. Telemedicine has evolved from being a research tool to a clinical service over the past years. ${ }^{1-4} \mathrm{~A}$ literature search demonstrates suitability and efficiency of teleophthalmology, especially in diseases where a digital imaging system is useful for diagnosis and intervention. ${ }^{2,5-7}$ In addition to the tele-eye care application, advantages of digital imaging systems include short examination time, electronic medical images, and the ability of nonophthalmologists to screen for diseases. In many developing countries where resources are unavailable/limited, the benefits of teleophthalmology have been tried and proven, especially in the underserved and remote population worldwide. ${ }^{8-11}$ However, utilization of teleophthalmology services is yet to gain wide acceptance in many countries due to various reasons. ${ }^{12,13}$ The majority of the current teleophthalmology services concentrate on patient screening and appropriate referral to experts. Some models also demonstrate efficient follow-up systems. ${ }^{14}$ 
Teleophthalmology mostly adopts the store-and-forward method, followed by interactive services and remote monitoring methods. ${ }^{15}$ Alternatively, a hybrid method including both store-and-forward and real-time teleexamination can be used for the provision of efficient teleophthalmology services.

Numerous studies have explored multiple benefits of teleophthalmology, such as reliability, cost-effectiveness, time efficiency, and accessibility, in scenarios where experts are unavailable. ${ }^{6,9,16-19}$ There are limited studies that demonstrate patient outcome in teleophthalmology services. Lembcke stated that "the best measure of quality is not how well or how frequently a medical service is given, but how closely the result approaches the fundamental objectives of prolonging life, relieving distress, restoring function, and preventing disability". ${ }^{20}$ Over the past decades, outcome assessment of health care system includes patients' assessments of their health, care, and services they receive. ${ }^{21}$ Outcomes, by and large, remain the ultimate validators of the effectiveness and quality of medical care. ${ }^{22}$ This review explores teleophthalmology models that have demonstrated better patient outcome along with making a significant societal impact.

\section{Methods}

A structured literature search was done in search engines such as PubMed, Medline, and Google Scholar using the following keywords - teleophthalmology OR telemedicine OR web based OR internet based AND patient satisfaction OR impact OR patient outcome OR efficiency, teleophthalmology OR telediabetic screening OR teleglaucoma OR tele ROP, teleophthalmology OR telescreening AND Diabetic retinopathy OR retinopathy of prematurity OR eye care OR glaucoma OR Retinal diseases OR macular diseases OR digital imaging OR retinal imaging OR anterior segment imaging OR primary eye care. One hundred and seventy five articles were reviewed. The articles that best fit the criteria of patient outcomes were included in the review. The detailed literature search resulted in 125 articles published over the past decade, and 67 of those were best fit for the current narrative review. Cross-sectional studies with minimum of level 4 evidence and above were included in this review. Studies that report patient outcomes, including those that used teleophthalmology models for screening for all sight-threatening eye diseases, were included. Studies which describe novel methodologies and technologies for possible use in teleophthalmology practices without details patient outcome measure were excluded.

We defined patient outcomes under two major domains:
1) Teleophthalmology as a clinical tool - impact in diagnosis and management.

2) Patient-defined outcome in terms of satisfaction and quality of life.

There are limited studies available exploring the realworld benefits of telemedicine, including patient-defined outcomes, in contrast to a vast number of studies demonstrating the benefits of telemedicine practice to be as good as routine clinical examination. This review describes the aforementioned objectives in two sections, namely, specialty/ disease-specific and comprehensive teleophthalmology practices.

\section{Specialty teleophthalmology}

\section{Neonatal teleophthalmology}

Neonatal teleophthalmology focus mainly on retinopathy of prematurity (ROP) screening. However, many such tele-ROP projects screen for other anatomical pathologies in addition to ROP screening. ROP is a vasoproliferative disorder of the developing retina of low-birth-weight preterm infants that potentially leads to blindness in a small but significant percentage of those infants. ${ }^{23}$ ROP being the leading cause of avoidable childhood blindness throughout the world, the increasing number of infants at risk for ROP is a major concern. ${ }^{24}$ The condition also requires continued patient review and monitoring of the vascular growth at the ora serrata. Telebased services can be used in realworld situations to create a virtual platform between the patient and expert. There are a good numbers of review articles (Table 1) reporting good reliability measures from numerous tele-ROP studies suggesting that telescreening using wide-field digital imaging of premature infant retina is more competent than traditional bedside binocular ophthalmoscopy.

Richter et $\mathrm{al}^{25}$ reported that the diagnosis of ROP by an expert via tele-ROP screening method required less time compared to bedside binocular indirect ophthalmoscopy. The study demonstrated reduced time commitment for the examining ophthalmologist when diagnosis was made in remote portal compared to bedside examination. Utilization of appropriate viewing platform of digital images improves time saving and accuracy of image analysis. Myung et $\mathrm{al}^{26}$ demonstrated the benefit of comparing digital images between examinations to identify accurately the vascular progression in ROP. The study described the advantage of using dynamic flickering image pairs, which provided faster response time without compromising accuracy of image analysis by expert, compared with static side-by-side image pairs. This method 
Table I Major findings of review articles on tele-ROP screening using wide-field digital imaging of premature infant retina

\begin{tabular}{|c|c|c|}
\hline Study & Main objective & Key finding \\
\hline Richter et $\mathrm{al}^{27}$ & $\begin{array}{l}\text { I) Compared six studies to find specificity and } \\
\text { sensitivity to identify any stage of ROP. } \\
\text { 2) Compared five studies reporting sensitivities and } \\
\text { specificities to diagnose moderate-to-severe ROP. }\end{array}$ & $\begin{array}{l}\text { I) Sensitivity } 76 \% \text { to } 97 \% \text { (except two studies, which reported } 46 \% \\
\text { and } 60 \% \text { ). Specificity } 89 \% \text { to } 100 \% \text { (except one study, which } \\
\text { reported specificity ranges from } 49 \% \text { to } 96 \% \text { ). } \\
\text { 2) Sensitivity } 71 \% \text { to } 100 \% \text { (except one study, which reported } 57 \% \text { ). } \\
\text { Specificity } 81 \% \text { to } 100 \% \text {. }\end{array}$ \\
\hline Vinekar et $\mathrm{al}^{10}$ & $\begin{array}{l}\text { Comparison of real-world tele-ROP programs } \\
\text { worldwide. Seven studies included. }\end{array}$ & Sensitivity ranges from $90 \%$ to $100 \%$ \\
\hline Weaver $\mathrm{DT}^{18}$ & $\begin{array}{l}\text { The study reviewed available evidences of digital } \\
\text { retinal imaging via telemedicine to examine } \\
\text { reliability, accessibility, and cost efficacy in ROP } \\
\text { screening (including current practice). }\end{array}$ & $\begin{array}{l}\text { Overall, the report concluded that digital retinal photography } \\
\text { has high accuracy for the detection of clinically significant ROP, } \\
\text { and additionally, provides potential advantages through objective } \\
\text { documentation of exam findings, improved recognition of disease } \\
\text { progression by comparison with prior photographs, and the } \\
\text { creation of image libraries for education and research. }\end{array}$ \\
\hline Kandasamy et $\mathrm{al}^{5}$ & $\begin{array}{l}\text { The study reviews the feasibility of using } \\
\text { nonophthalmologist staff for tele-ROP screening, } \\
\text { efficacy of digital imaging of infant retina in ROP } \\
\text { diagnosis as part of telemedicine, and cost- } \\
\text { effectiveness of tele-ROP screening. }\end{array}$ & $\begin{array}{l}\text { ROP diagnosis using telemethod. Sensitivity ranges: } 0.46-0.97 \text {. } \\
\text { Specificity ranges: } 0.89-1 \text {. Interobserver reliability }(\kappa) \text { ranged from } \\
0.67 \text { to } 0.89 \text {. } \\
\text { Sensitivity: } 100 \% \text {, specificity: } 97.9 \% \text {, PPV: } 84.6 \%, \text { NPV: } 100 \% \text {. } \\
\text { Cost saving is better with telemedicine than with bedside BIO for } \\
\text { ROP management. } \\
\text { Experts are required for accurate image analysis when compared } \\
\text { with image analysis by trained nonexperts. }\end{array}$ \\
\hline Fierson et $\mathrm{al}^{2}$ & $\begin{array}{l}\text { This systematic review focuses on available } \\
\text { literature on tele-ROP using digital imaging } \\
\text { and highlights practical and risk management } \\
\text { considerations that should be used when tele-ROP } \\
\text { screening is used. }\end{array}$ & $\begin{array}{l}\text { A total of } 486 \text { studies retrieved, eleven studies selected for detailed } \\
\text { analysis and classified as level I, } 2 \text {, and } 3 \text { studies. } \\
\text { Level I studies ( } N=8 \text { ). } \\
\text { ROP Zone I any stage with disease/Zone I stage } 3 / \text { Zone I I stage } 2 \\
\text { or } 3 \text { with plus disease. } \\
\text { Mean sensitivities } 92.8 \% \text { specificity } 94 \% \text {. } \\
\text { Level } 3 \text { studies ( } N=3 \text { ) from real-world tele-ROP programs reported } \\
\text { high accuracy to detect clinically significant ROP through remote } \\
\text { site interpretation of wide-angle retinal image. } \\
\text { Moderate (levels } 2 \text { and } 3 \text { ) quality supports the use of retinal } \\
\text { imaging to identify patients with clinically significant or referral- } \\
\text { warranted ROP for ophthalmic evaluation and management. } \\
\text { However, the current imaging system collects less information than } \\
\text { what is required to fully stage the disease based on international } \\
\text { classification of ROP. }\end{array}$ \\
\hline
\end{tabular}

Abbreviations: ROP, retinopathy of prematurity; PPV, positive predictive value; NPV, negative predictive value; BIO, binocular indirect ophthalmoscopy.

helps assess progression of the retinal condition by enhancing subtle changes in the series of images.

There are good tele-ROP practice models that have evolved over the past decades. The Stanford University Network for Diagnosis of Retinopathy of Prematurity (SUNDROP) ${ }^{28}$ is an ongoing, real-world tele-ROP network in northern America. A team of trained neonatal intensive care unit (NICU) nurses capture infant retinal image as per recommendation. The captured images and patient data are sent to experts at a reading center for analysis. Primary telebased examination outcomes were treatment warranted (TW)-ROP and structural anomalies causing blindness. The study (2005-2011) demonstrated remote image-reading sensitivity $=100 \%$, specificity $=99.8 \%$, positive predictive value $(\mathrm{PPV})=95.5 \%$, and negative predictive value
$(\mathrm{NPV})=100 \%$. Of the screened 608 preterm infants $(2,169$ examinations), 3.6\% had TW-ROP. Weaver et $\mathrm{al}^{11}$ reported tele-ROP screening using SUNDROP model in 137 infants. Around 9.5\% (13 patients) of the infants diagnosed with referral warranted ROP and were sent for treatment. Nine of them received laser treatment, and the other five infants were advised follow-up examination. Good outcome was reported in all cases treated with laser.

Karnataka Internet Assisted Diagnosis of Retinopathy of Prematurity (KIDROP) program ${ }^{10}$ is a well-structured tele-ROP tool that serves rural South India. Retinal imaging (modified photo-ROP) is performed by trained validated technicians at levels 1, 2, and 3. Level 3 technicians grade images and transfer them to experts on iPhone/laptop with specially designed software to generate ROP report. The 
accredited trained technician determines on-site whether the baby needed follow-up/treatment/discharge based on the triage algorithm created by experts. The rural multicenter study (2011-2015) demonstrated successful screening of 7,106 preterm infants (20,214 examination) from 36 rural NICUs in South India. Around $3.57 \%$ of the infants required treatment for ROP, and they underwent treatment. Of the treated eyes, eleven eyes had unfavorable outcome, including three infants who were lost to follow-up. The study reported that no infant in the study region developed unscreened stage 4 or 5 ROP. The rural ROP incidence was $22.39 \%$, and treatmentrequiring ROP was found in $3.57 \%$.

Lorenz et $\mathrm{al}^{29}$ reported the 6-year (2001-2006) results of multicentric tele-ROP. A total of 1,222 infants were screened in 3,230 examinations. Infant retinal imaging was carried out by ophthalmologists in the peripheral centers and the images were transferred to experts in the reading center. Approximately $3.50 \%$ and $3.76 \%$ had treatment-requiring ROP and suspected treatment-requiring ROP (STR-ROP), respectively.

These real-time or quasi real-time tele-ROP screening programs demonstrated the efficiency of the system at identifying the disease and timely referral of high-risk infants to experts. These programs have also provided good pointof-care treatment services, thus enhancing patient outcome. However, more structured studies are required to assess the patient outcome, parent perceptions, and concerns on such systems compared to traditional face-to-face examination.

\section{Diabetic retinopathy}

Around 285 million people are visually impaired worldwide, of whom 39 million are blind. ${ }^{30}$ Approximately 65\%-82\% of the visually impaired or blind are aged 50 years or older. Modern sedentary lifestyle increased the risk of more people affected by cardiovascular and metabolic diseases. It is estimated that, globally, 552 million people will be affected with diabetes by $2030 .{ }^{31}$ During this period, there will be an increase of $69 \%$ and $20 \%$ in the numbers of adults with DM in developing countries and developed countries, respectively.

Diabetic retinopathy (DR)-related visual impairment has become a significant health problem affecting the productive age group. Clinical features of DR have a detectable presymptomatic stage. Early detection and timely treatment can decrease the risk of severe loss of vision. International diabetes screening guidelines recommend DR screening in early stages to avoid related complications. In type 1 diabetic patients, eye examination must be performed after 5 years of diagnosis, with subsequent annual follow-up examination. In type 2 diabetic patients, eye examination must be performed at the time of diagnosis and at subsequent annual follow-up examination.

Owsley et $\mathrm{al}^{32}$ reported that approximately one in five diabetic patients were identified with DR during tele-DR screening in clinics serving the ethnic/racial minority population of the USA. Internet-based teleophthalmology model is accurate and reliable in identifying patients requiring detailed clinical examination and intervention for clinically significant macular edema (CSME) and/or proliferative diabetic retinopathy (PDR). ${ }^{6}$

Tele-DR screening using imaging technologies are a reliable, accurate, sustained, and cost-effective method to identify subjects with DR, grade disease according to its severity, and aid in management decisions. ${ }^{3,6,33,34}$ The development of global teleophthalmology strategy complements the traditional health care system in meeting the eye care needs of all people with diabetes.

DR assessment, with other health programs or facilities, improves access to the eye care and efficiency in terms of treatment, time, cost, and number of visits to experts' offices. ${ }^{35}$

The American Telemedicine Association (ATA) recommends different levels of validation approach to practice DR telescreening. ${ }^{36}$

Category 1 validation identifies patients who have no or minimal DR and those who have more than minimal DR.

Category 2 validation identifies patients who do not seem to have sight-threatening DR and those who have potentially sight-threatening DR and require prompt referral and possible laser surgery (severe nonproliferative DR [NPDR] or worse).

Category 3 validations allow patient treatment to match clinical recommendations based on clinical retinal examination through dilated pupils.

Category 4 validation indicates that a program can replace Early Treatment Diabetic Retinopathy Study (ETDRS) photographs in any clinical or research program.

Silva et $\mathrm{al}^{37}$ reported that validated teleophthalmology tool increased the rate of annual retinal examination from $50 \%$ to $75 \%$. There was an increase of $51 \%$ in the number of subjects undergoing laser treatment to prevent severe visual loss.

Images obtained with nonmydriatic digital camera are efficient in detecting DR and grading the disease process. ${ }^{38}$ Rubio et al ${ }^{39}$ reported that 2,435 diabetic patients (age: $>18$ years, mean: 62 years) underwent retinal imaging with a nonmydriatic retinograph (Topcon TRC-NW 100, 
Vision Systems Inc., Tarpon Springs, FL, USA) handled by a trained nurse. Remote reading of images is done by an expert for diagnosis and treatment guidance. Of the 436 patients identified with DR, 86 patients had severe NPDR (12.16\%), PDR (2.29\%), and maculopathy associated to retinopathy (4.82\%) and were referred to hospital for intervention/detailed examination.

However, incorporating stereoscopic fundus photography provides high specificity in detecting CSME, and hence may reduce the number of patients referred for hospital-based clinical examination and increase the cost-effectiveness. Rudnisky et $\mathrm{al}^{6}$ report a $20 \%$ reduction in referral requiring patients when stereoscopic imaging technique is used. Also found that stereo imaging has high specificity $(92.9 \%)$ in detecting CSME.

Boucher et $\mathrm{al}^{19}$ described DR screening in 3,505 known diabetic individuals using a Category 3 teleophthalmology protocol implemented through mobile screening imaging units in Canada. Thirty-eight percentage of the patients reported having their first ever dilated retinal examination during the telescreening. Approximately $22.5 \%$ of all diabetic patients had DR changes, and $1.8 \%$ of the patients had severe DR. Nine percentage of the patients recommended for repeat eye examination within 6 months because of DR. Incidental findings were found in $23 \%$, with the majority finding being dry macular degeneration and cataract.

Cavallerano et $\mathrm{al}^{40}$ reported a retrospective study, where category 3 teleophthalmology protocol was utilized to screen 1,219 patients $(2,437$ eyes $)$ with DM, impaired fasting glucose, or impaired glucose tolerance. Around $24 \%$ of the patients had DR changes in the retina. Approximately $1.4 \%$ had early diabetic macular edema and $0.7 \%$ had CSME. Of the 908 patients with either no DR or mild NPDR in the eye with the more severe disease, $58.7 \%$ required referral for incidental ocular finding other than DM eye changes.

The use of license-free Web-based software, and standard interface with flexible protocols allowed primary care providers to adopt retinopathy screening with minimal effort and resources. A study using such strategy reported that the referral rate for the sight-threatening retinopathy is $8.21 \%$, with approximately $8 \%$ being referred for other conditions. ${ }^{41}$

Kim et $\mathrm{al}^{9}$ demonstrated teleophthalmology service model in Vancouver Island, Canada, to screen retinal health and eye disease. The study also evaluated multiple quality measures of the model. The telemobile unit included a team of two technicians and a trained nurse. The unit collected details on demographics, history, visual function, intraocular pressure (IOP), and a three-dimensional digital image of the anterior and posterior segments of the eye. The collected medical data were then transferred to ophthalmologists for analysis. Further communications were made upon the remote grading of images and recommendation by the ophthalmologist. A total of 524 diabetic and at-risk subjects were screened. Approximately $26.7 \%$ of them were referred for treatment. Three-fourths of the referrals were to a general ophthalmologist, $12 \%$ were to retina specialist, and $10 \%$ were to optometrist.

OPHDIAT $^{\circ}$ (Ophthalmology Diabetes Telemedicine) $^{42}$ in France screened 13,777 diabetic patients (2004-2006) for DR. DR was detected in $23.4 \%$ of the patients. Seven hundred and seventy seven $(5.6 \%)$ patients with undiagnosed DR stage (severe NDPR or PDR and/or macular edema) received urgent referral to an ophthalmologist for laser treatment. After screening, 25.2\% patients were referred to an ophthalmologist for reasons, including DR, cataract, and/or nongradable photographs.

\section{Glaucoma}

There are limited studies which demonstrate adequate system to overcome the possibilities of missing new disease or disease progression in teleglaucoma services. A systematic review by Thomas et $\mathrm{al}^{43}$ reported that teleglaucoma is less sensitive (pooled sensitivity 83.2\% [95\% CI: 77\%-88.1\%] and more specific (pooled specificity 79\% [95\% CI: $66.8 \%-87.6 \%$ ] than face-to-face clinical examination in detecting glaucoma. Time saving was also reported with teleglaucoma. There was reduction for patient travel time of 61.23 hours. The mean time spent in the tele-glaucoma clinic ( $81.7 \pm 6$ minutes) was less compared to face-to-face clinical examination (116 \pm 2.5 minutes). Patient satisfaction with teleglaucoma was higher. A handful of teleophthalmology projects incorporate teleglaucoma with screening or follow-up of other eye diseases.

"EyeMo" mobile tele-eye care unit ${ }^{14}$ in Finland combines DR screening and follow-up of stable glaucoma patients. Glaucoma patients were monitored for IOP, visual field, and retinal imaging of optic disc and nerve fiber layer was undertaken.

Li et $\mathrm{al}^{44}$ reported a remote analysis between stereoscopic digital disc image and $35 \mathrm{~mm}$ slide photograph of 32 eyes. The pilot study demonstrated $100 \%$ agreement on optic disc parameters such as vertical elongation, barring of vessels, bayoneting of vessels, and drance hemorrhage, and a $96.2 \%$ agreement on focal notching of rim and rim pallor.

Kassam et $\mathrm{al}^{45}$ described tele-glaucoma services in University of Alberta and Western Australia. The Alberta 
model consists of collaborative approach by ophthalmologist and optometrist and a store-and-forward approach is utilized. The structured teleglaucoma care program has both remote and in-house glaucoma diagnosis and management. All the subjects undergo the glaucoma screening package, which includes standardized history taking, slit-lamp examination, corneal pachymetry, fundus photographs, visual field tests such as frequency doubling technology (FDT) perimetry or Humphrey Visual Fields, and optical coherence tomography (OCT) or Heidelberg retinal tomography (HRT). The medical data are then stored and forwarded to glaucoma subspecialists for analysis. The report, along with recommendations, are generated and sent back to appropriate professionals. In Australia, the tele-glaucoma program is mainly real-time consultation with glaucoma specialist via VoIP (Voice-over Internet Protocol) services from primary eye care clinic/physician clinic. The medical data are stored and forwarded to the expert for real-time consultation using Remote I, a specially designed tablet device. The University of Alberta study reported remote grading of 195 glaucoma cases, including 62 in-house services. The average reporting time was 7 days for both remote and in-house.

Tuulonen et $\mathrm{al}^{46}$ compared interactive, real-time teleglaucoma consultation of 29 glaucoma patients of a rural health center with a control group of 41 glaucoma patients in a university glaucoma clinic. In this pilot study, rural health center patient examination was done by ophthalmic resident and general practitioner. The study demonstrates equal satisfaction among patients in both groups. Approximately $96 \%$ of the telegroup preferred to have teleconsultation on subsequent follow-up also, voting for reduced traveling, cost, and time.

Verma et $\mathrm{al}^{47}$ reported clinical patient outcome (20082012) of 247 subjects (open-angle glaucoma suspects or definite early open-angle glaucoma) referred to teleglaucoma consultation. The study demonstrated that about three-fourths of the subjects did not require face-to-face evaluation with specialist and that they are managed through remote collaboration. Of all glaucoma (31.1\%), glaucoma suspects (42.1\%), and unaffected (26.7\%), around $27 \%$ of all referred for clinical glaucoma evaluation. Around $87 \%$ of the patients with definite glaucoma and $28 \%$ of the glaucoma suspects received treatment before being seen for face-to-face examination by specialist.

A tele-glaucoma screening initiative in the Netherlands ${ }^{48}$ reported that 1,729 subjects underwent tele-glaucoma screening by an optometrist using nerve fiber analyzer. Medical data were transferred to trained technicians in the hospital. Image quality was satisfactory in $89 \%$ of the cases. Eighty new cases were detected. A high level of agreement (81\%) was found between the optometrists and the hospital in grading the test result as normal or suspect. About one-fourth of all required additional hospital examination, including $11 \%$, consulted a specialist.

Wright et $\mathrm{al}^{49}$ described tele-glaucoma services in the UK supervised by a glaucoma specialist. This is the largest tele-glaucoma study reported so far (24,257 patients). The mobile teleteam consists of optometrists, technicians, diagnostic equipment, and support tools. The grading of the test results were done in accordance to the predesigned algorithm (normal, stable, low risk, unstable, and high risk). The transferred medical data were reviewed by the specialist and compared with the test results of the optometrist. This virtual patient review allows for patient management by optometrists at the community level and also for online supervision from a specialist. There was good agreement $(87 \%)$ between the optometrist and specialist, with a moderate $\kappa$ value of 0.69 . Of all those who were screened, only $0.054 \%$ were found to be at high risk by the specialist but were missed by optometrist. The study suggests that virtual clinic supervision by specialist is beneficial to reduce the misdiagnosis and review visits.

A teleglaucoma study from Kenya ${ }^{16}$ compared clinic examination by comprehensive ophthalmologist (CO) to teleglaucoma examination by glaucoma specialist. All the subjects underwent comprehensive eye examination, dilated fundus evaluation by $\mathrm{CO}$, visual filed testing using FDT, and fundus imaging. The remote reading of medical data was compared with clinic examination by $\mathrm{CO}$. The study reported moderate agreement on vertical cup-to-disk ratio (VCDR) between clinic and tele-glaucoma screening. Teleglaucoma showed a sensitivity $41.3 \%$ and a specificity $89.6 \%$ for diagnosing glaucoma with PPV 77.58\% and NPV 82.2\%. The study pointed that relatively low reliability indices are due to difference in the grading physician's expertise, low image quality, difference in adopted grading system between the physicians, etc. Similar studies from African countries demonstrate the keenness for application and utilization of teleophthalmology services in that region too.

Screening for glaucoma is relatively limited considering the complexity of the disease. Tele-glaucoma services have a great role in supporting periodic monitoring, timely referral, and in enhancing better compliance to medical care.

\section{Macular degeneration}

Kanagasingam et $\mathrm{al}^{50}$ explored the possibilities of telescreening of age-related macular degeneration (ARMD) using automated and semiautomated grading systems and retinal image analysis techniques for early detection and follow-up 
of the disease. OCT imaging modality is appropriate for telemedicine-based screening and management.

De Bats et $\mathrm{al}^{51}$ reported the ability of detecting ARMD remotely using nonmydriatic digital fundus camera. Approximately $16 \%$ of the gradable digital images were identified having ARMD. Age, positive family history of ARMD, and postcataract surgery are the risk factors for ARMD.

Incorporating OCT images in teleophthalmology care focusing on macular degeneration would enhance efficiency in terms of prompt care. ${ }^{52}$

\section{Patient satisfaction in teleophthalmology}

Telophthalmology is being practiced all over the world to improve access to care and, at many at times, to facilitate the prioritization in specialty care. Numerous studies have shown that patients are satisfied with the telemedicine mode of health care delivery. ${ }^{53}$ Various satisfactions survey studies in teleophthalmology report good satisfaction level, but many are limited by smaller sample size (Table 2).

Lee et $\mathrm{al}^{54}$ demonstrated positive parent perception toward digital retinal imaging and attitudes toward telemedicine, but expressed preference to face-to-face care. Many parents were highly in favor of having digital images attached to the health record $(4.4 \pm 0.6)$ and agreed that "technology will improve the quality of medical care" $(4.3 \pm 0.6)$. Parents were apprehensive about the reliability of digital cameras and computers (3.8 \pm 0.8$)$. There was least agreement on "technology will result poor patient-doctor relationship" (2.6 \pm 1.1$)$.

Paul et a ${ }^{55}$ conducted a survey on 348 patients (age range: 18-83 years). Approximately $99.8 \%$ of the subjects reported good satisfaction on teleophthalmology consultation. Threefourths of the subjects felt that they received enough attention from the ophthalmologist at the base hospital during teleconsultation. Nearly all subjects voted for teleophthalmology as their choice for eye examination.

Kumar et $\mathrm{al}^{56}$ reported a 1 -year study of remote interactive teleophthalmology consultation facility provided to a remote location $940 \mathrm{~km}$ away from a base hospital in Australia. Practitioners at the center transferred medical data, including history, demographic details, and digital images of anterior and posterior segments and IOP for the analysis. 118 patients (Age: 4 to 73 years) took up the service. Greater than $90 \%$ of subjects utilized the facility to screen for glaucoma and DR. Only 3\% of the subjects required referral after teleconsultation. Approximately $36 \%$ subjects required regular follow-up examination. Approximately $98 \%$ of the subjects were satisfied with remote-based consultation and observed that it was convenient. Face-to-face examination with ophthalmologist was not a major concern to three-fourths of the subjects.

Court et $\mathrm{al}^{57}$ studied patient satisfaction level, acceptance and quality of patient education among patients attending virtual glaucoma clinic and standard clinic. The study reported that the patients attended virtual glaucoma clinic expressed high level of patient satisfaction and patient understanding about the disease, similar to standard clinic. The acceptance level were equal for both the set up. Patient knowledge and understanding about their condition was high in the virtual clinic group.

Kurji et a ${ }^{59}$ compared patient satisfaction in DR screening with teleophthalmology with face-to-face clinical examination in a sample of 57 subjects. Approximately $88 \%$ of the patients were completely satisfied with teleophthalmology. More than $50 \%$ of the patients preferred this method for their future screening examination, voting convenience, and decreased consultation time.

Table 2 Patient satisfaction in teleophthalmology services

\begin{tabular}{|c|c|c|}
\hline Study & Teleophthalmology mode/number of subjects surveyed & Satisfaction \\
\hline Paul et $\mathrm{al}^{55}$ & $\begin{array}{l}\text { Rural mobile teleophthalmology unit/348 subjects } \\
\text { (age range: } 18-83 \text { years) }\end{array}$ & $99.8 \%$ \\
\hline Kumar et $\mathrm{al}^{56}$ & Remote teleophthalmology center/II8 subjects & $98 \%$ \\
\hline Tuulonen et al ${ }^{46}$ & $\begin{array}{l}\text { Real-time interactive teleconsultation at rural primary care center } \\
\text { compared with face-to-face clinical examination }\end{array}$ & $\begin{array}{l}\text { Equal satisfaction between the two groups. } 96 \% \text { of } \\
\text { the telegroup preferred follow-up examination via } \\
\text { teleconsultation. }\end{array}$ \\
\hline Court et $\mathrm{al}^{57}$ & $\begin{array}{l}\text { Virtual glaucoma clinic ( } 135 \text { patients) compared with control group } \\
\text { of normal clinic patients ( } 100 \text { patients) }\end{array}$ & $\begin{array}{l}\text { High satisfaction in both the clinics ( } 4.5 / 5 \text { and } 4.6 / 5) \text {. } \\
\text { Reported high awareness among virtual clinic patients }\end{array}$ \\
\hline Sreelatha et $\mathrm{al}^{58}$ & $\begin{array}{l}\text { VA testing in remote portal compared with face-to-face } \\
\text { examination }\end{array}$ & $\begin{array}{l}87 \% \text { of the patients reported high satisfaction with tele } \\
\text { VA measurement }\end{array}$ \\
\hline Kurji et al ${ }^{59}$ & $\begin{array}{l}\text { DR screening in multidisciplinary diabetic clinic ( } 57 \text { subjects): } \\
\text { assessment done for patient preference between teleophthalmology } \\
\text { and face-to-face ophthalmologist evaluation }\end{array}$ & $\begin{array}{l}88 \% \text { satisfied with teleophthalmology services. } \\
\text { Patients preferred the teleophthalmology option for } \\
\text { future screenings. Convenience, reduced examination } \\
\text { time, and visualization of patient's own retina were the } \\
\text { support factors. }\end{array}$ \\
\hline
\end{tabular}

Abbreviations: VA, visual acuity; DR, diabetic retinopathy. 


\section{Comprehensive teleophthalmology projects}

There are many successful comprehensive teleophthalmology projects all over the world. A combination of store-andforward and interactive methods are used. Many studies demonstrate successful integration of teleophthalmology in primary eye care setup. Referral hospitals connected to mobile units, specially designed vans equipped with ophthalmic instruments and internet connectivity accompanied by optometrist or technicians and other support staffs, travel to underserved/rural areas. Gupta et a ${ }^{60}{ }^{6}$ reported that diagnostic and management decisions using teleophthalmology have high level of agreement with in-clinic assessment.

Johnson et $\mathrm{al}^{61}$ reported on real-time teleophthalmology practice in rural Western Australia by a general ophthalmologist. Of the 100 video consultations $(85$ subjects, age range: 7-92 years), 35 consultations required face-to-face examination with an ophthalmologist. The main reasons for a consultation were for a red eye, DR screening, or glaucoma follow-up. About one-third of the teleconsultation resulted in recommendation of face-to-face examination with an ophthalmologist. A few cases required emergency referral to the hospital.

Muccioli et $\mathrm{al}^{62}$ described the teleophthalmology experience in Brazil via Virtual Diagnostic Center. One of their studies reported $74 \%$ accuracy in teleophthalmology compared to face-to-face clinical examination. A study by Ribeiro et $\mathrm{a}^{63}$ validated teleophthalmology mobile system to screen ocular emergency cases in remote and underserved areas in Brazil. A mobile phone application, mHealth Sana platform, was used to image anterior segment and transfer the patient data, including questionnaires, for remote assessment. The study found that teleophthalmology showed a sensitivity of $92.85 \%$, a specificity of $81.94 \%$, an accuracy of $85 \%$, a PPV of $66.66 \%$, and an NPV of $96.72 \%$ in detecting ocular emergencies.

Teleophthalmology in Canada is being utilized by more than 100 communities. Teleophthalmology services to aboriginal communities in rural and underserved areas of Canada are described elsewhere in the article. On comparing the financial benefit between tele- and traditional examination, teleophthalmology reduced the cost per head by CAD $\$ 56.34$ compared to traditional face-to-face examination. It was observed that there was also continued increase in cost saving over the period for teleophthalmology. A study observed decreased rate of referrals compared to program start year, attributed to the improved health outcome such as reduced need for treatment and stabilization. ${ }^{9}$
SNTOP (Sankara Netralaya Teleophthalmology Project), ATN (Aravind Tele Network), KIDROP, etc, are some of the successful ongoing teleophthalmology projects in India. SNTOP $^{8}$ focuses on comprehensive eye examination of subjects from rural areas of south India. The customized mobile van unit is equipped with ophthalmic examination unit and satellite connectivity. The preliminary examination and screening alone is done by the optometrist. The subjects undergo anterior and posterior segment imaging. Medical data are then transferred to the expert in base hospital, and then real-time interaction via videoconferencing between the expert, the examining optometrist, and the patient is established. John et a ${ }^{64}$ reported that 54,751 patients underwent evaluation over a period of 1.5 years. Major cause of avoidable blindness was refractive error $(59 \%)$ followed by cataract $(30 \%)$, retinal diseases $(3.3 \%)$, and corneal diseases $1 \%$. Verma et $a^{165}$ reported remote diagnosis of adnexal and orbital diseases. The study was done in a rural region that does not have quality medical care. All subjects underwent preliminary examination by optometrist and imaging of external eye, and anterior and posterior segment. The medical data were transferred to experts in the base hospital and real-time interaction was established through videoconferencing between the expert, the optometrist, and the patient. Around 22,043 subjects were screened. Approximately 3,497 patients had teleconsultation with an expert, of whom, $2.88 \%$ had diseases of eyelids, adnexa, and orbit. More than $60 \%$ of the subjects diagnosed with diseases to lid adnexa and orbit were surgically treatable, whereas approximately $13 \%$ were medically treatable and $25.7 \%$ had potentially sight- and life-threatening problems. All subjects received treatment/referral guidance as per each case requirement. This teleophthalmology examination also diagnosed subjects with refractive error, cataract, and retinal pathologies, and management guidance was given accordingly.

Gonzalez et $\mathrm{al}^{17}$ reported teleophthalmology practice in Spain connecting primary health care center to reference hospital. The screening was mainly for retinal pathologies including glaucoma. One hundred and thirty nine subjects underwent teleophthalmology consultation using the storeand-forward method. Remote reading of retinal image was done. Approximately $40 \%$ of the patients were recommended for clinical examination by the ophthalmologist because of poor image quality (13\%), fundus changes (17\%), and image features that suggested eye fundus alterations but were not clear enough to be diagnosed (10\%). This study highlights benefits of teleophthalmology, including reducing conventional traveling expense for the patients. 
Teleophthalmology network at a remote location in the People's Republic of China was reported by Chen et al. ${ }^{66}$ The study focused on elderly population (113 subjects, age above 40 years). The subjects were screened mainly for retinal pathologies such as DR, ARMD, and glaucoma. The remote reading of images was done by a retina specialist. Approximately $12 \%$ of the patients had age-related macular edema. Another 12\% had optic disc problems (mild and moderate), and $22 \%$ had high IOP.

\section{Emergency teleophthalmology}

Digital imaging of anterior and posterior segment along with videoconferencing and transfer of fundus images allow for effective provision of substantial eye care in emergency services. Teleopthalmology services play an increasing role in emergency eye care, including for urgent diagnosis, treatment, and prompt referral. ${ }^{67}$

Ribeiro et $\mathrm{l}^{63}$ validated teleophthalmology mobile system to screen ocular emergency cases in remote and underserved areas in Brazil. A mobile phone application, mHealth Sana platform, was used to image anterior segment and transfer the patient data, including questionnaires, for remote assessment. The study found that teleophthalmology showed sensitivity $92.85 \%$, specificity $81.94 \%$, accuracy $85 \%$, PPV 66.66\%, and NPV $96.72 \%$ in detecting ocular emergencies.

Kumar et $\mathrm{l}^{68}$ reported the suitability of teleophthalmology integrated with rural emergency eye care services.

\section{Impact of teleophthalmology services}

Cook et $\mathrm{al}^{69}$ demonstrated the impact of teleophthalmology in diagnosis, management, outcome, and medical education. The study was done in part to explore the possibility of incorporating teleophthalmology into the health care system in South Africa and study its role in vision 2020. Ninety patients (113 consultation, mostly retinal and neuroophthalmology cases) were examined. Impact on diagnosis and management was $46 \%$ and $78 \%$, respectively. Impact on outcome was categorized as visual health and general health. This study reported an improvement of $63 \%$ in visual health and 39\% in general health. Approximately $13 \%$ of the patients showed major improvement in quality of life, and another $13 \%$ showed minor improvement in quality of life. It was mentioned that detach in $12 \%$ of the cases may have been prevented. Though the study showed the positive impact of teleophthalmology to the patient and care providers, the current need of ophthalmic service is beyond the scope of teleophthalmology services. The study concluded that teleophthalmology has no direct application in this first phase of Vision 2020 in South Africa as its focus is mainly on cataract and refractive error management.

Kumar et $\mathrm{al}^{56}$ reported impact assessment of teleophthalmology services on diagnosis, management, outcomes and satisfaction, and cost estimation of teleophthalmology service for a period of 1 year. Greater than $90 \%$ of subjects utilized the facility to screen glaucoma and DR. Only $3 \%$ of subjects required referral after teleconsultation. Another $36 \%$ subjects required regular follow-up examination. Approximately $98 \%$ of the subjects were satisfied with remote-based consultation and observed that it was convenient. Face-to-face examination with ophthalmologist was not a major concern to $75 \%$ of the subjects. Estimated cost of teleophthalmology consultation per patient was $\$ 279.96$. Cost neutral analysis estimated the decrease in cost to US $\$ 107.72$, when more number of patients utilizes the facility.

Chasan $\mathrm{JE}$ et $\mathrm{al}^{70}$ reported a retrospective study done in the USA to find out the effect of community-based diabetic teleretinal screening on eye care use and resources. Of the 1,935 patients, screened 24\% were referred to the eye clinic for detailed examination and management. Another 56\% of the referred patients underwent eye examination within 2 years of the telescreening. The agreement for the diagnosis between telescreeing and face-to-face clinical examination was $90.4 \%$ and sensitivity $73.6 \%$. The average total cost per patient estimated through Medicare physician fee schedule were US \$968.75 and US \$130.17 for patients seen in the eye clinic and patients undergoing imaging in primary care, respectively. Workload involved for eye care was $1,490.48$ RVUs (relative value units). The study concludes that teleretinal imaging is effective for screening sight-threatening conditions. The authors also demonstrate the need to take measures to reduce the resource burden.

\section{Reimbursement of teleophthalmology services}

A well-structured reimbursement strategy is necessary for the sustainability of telehealth. Developed countries like USA, Australia, and Canada have reimbursement schemes through government funds and insurance policies. However, this teleophthalmology reimbursement policy varies between the countries and within the countries. ${ }^{71}$ In developing countries where teleophthalmology is not widely practiced, reimbursement policies are not well defined. This remains one of the major barriers in practicing teleophthalmolgy widely. Effective utilization of teleophthalmology along with reimbursement of service will be effective in achieving goals of VISION 2020 in many countries. ${ }^{72}$ 


\section{Conclusion}

Numerous teleophthalmology studies demonstrate that diagnosing, monitoring, and managing of patients with vascular proliferative disease (ROP, DR, ARMD, etc) and optic nerve pathologies, such as glaucoma, through a remote portal by a specialist are comparable to traditional face-to-face clinical examination. Teleophthalmology produces the same desired clinical outcome as the traditional system. Allowing specialists to provide care over a large region through a remote portal improves health outcome. High satisfaction level and acceptance is reported in the majority of the studies because of increased accessibility and reduced traveling cost and time.

\section{Disclosure}

The authors report no conflicts of interest in this work.

\section{References}

1. Sood S, Mbarika V, Jugoo S, et al. What is telemedicine? A collection of 104 peer-reviewed perspectives and theoretical underpinnings. Telemed J E Health. 2007;13(5):573-590.

2. Fierson WM, Capone A Jr; American Academy of Pediatrics Section on Ophthalmology; American Academy of Ophthalmology, American Association of Certified Orthoptists. Telemedicine for evaluation of retinopathy of prematurity. Pediatrics. 2015;135(1):e238-e254.

3. Surendran TS, Raman R. Teleophthalmology in Diabetic Retinopathy. J Diabetes Sci Technol. 2014;8(2):262-266.

4. Strouthidis NG, Chandrasekharan G, Diamond JP, Murdoch IE. Teleglaucoma: ready to go? Br J Ophthalmol. 2014;98(12):1605-1611.

5. Kandasamy Y, Smith R, Wright I, Hartley L. Use of digital retinal imaging in screening for retinopathy of prematurity. J Paediatr Child Health. 2013;49(1):E1-E5.

6. Rudnisky CJ, Tennant MT, Weis E, Ting A, Hinz BJ, Greve MD. Web-based grading of compressed stereoscopic digital photography versus standard slide film photography for the diagnosis of diabetic retinopathy. Ophthalmology. 2007;114(9):1748-1754.

7. Taylor CR, Merin LM, Salunga AM, et al. Improving diabetic retinopathy screening ratios using telemedicine-based digital retinal imaging technology: the Vine Hill study. Diabetes Care. 2007;30(3):574-578.

8. Prathiba V, Rema M. Teleophthalmology: A Model for Eye Care Delivery in Rural and Underserved Areas of India. Int J Family Med. 2011;2011:683267.

9. Kim J, Driver DD. Teleophthalmology for first nations clients at risk of diabetic retinopathy: a mixed methods evaluation. JMIR Med Inform. 2015;3(1):e10.

10. Vinekar A, Jayadev C, Mangalesh S, Shetty B, Vidyasagar D. Role of tele-medicine in retinopathy of prematurity screening in rural outreach centers in India - A report of 20,214 imaging sessions in the KIDROP program. Semin Fetal Neonatal Med. 2015. pii: S1744-165X(15) 00053-0.

11. Weaver DT, Murdock TJ. Telemedicine detection of type 1 ROP in a distant neonatal intensive care unit. JAAPOS. 2012;16(3):229-233.

12. Kumar KR, Yogesan K, Constable IJ. Tele-ophthalmology in India. Is it here to stay? Indian J Ophthalmol. 2003;51(4):295-296.

13. Pérez GM, Swart W, Munyenyembe JK, Saranchuk P. Barriers to pilot mobile teleophthalmology in a rural hospital in Southern Malawi. Pan Afr Med J. 2014;19:136.

14. Hautala N, Hyytinen P, Saarela V, et al. A mobile eye unit for screening of diabetic retinopathy and follow-up of glaucoma in remote locations in northern Finland. Acta Ophthalmol. 2009;87(8):912-913.

15. Wu Y, Wei Z, Yao H, et al. TeleOph: A Secure Real-Time Teleophthalmology System. IEEE Trans Inf Technol Biomed. 2010;14(5): $1259-1266$.
16. Kiage D, Kherani IN, Gichuhi S, Damji KF, Nyenze M. The Muranga Teleophthalmology Study: Comparison of Virtual (Teleglaucoma) with in-Person Clinical Assessment to Diagnose Glaucoma. Middle East Afr J Ophthalmol. 2013;20(2):150-157.

17. Gonzalez F, Iglesias R, Suarez A, Gomez-Ulla F, Perez R. Teleophthalmology link between a primary health care centre and a reference hospital. Med Inform Internet Med. 2001;26(4):251-263.

18. Weaver DT. Telemedicine for retinopathy of prematurity. Curr Opin Ophthalmol. 2013;24:425-431.

19. Boucher MC, Desroches G, Garcia-Salinas R, et al. Teleophthalmology screening for diabetic retinopathy through mobile imaging units within Canada. Can J Ophthalmol. 2008;43(6):658-668.

20. Lembcke PA. Evolution of the medical audit. JAMA. 1967;199(8): 543-550.

21. Allyson Ross Davies. Patient defined outcomes. Qual Health Care. 1994;3(Suppl):6-9.

22. Avedis Donabedian. Evaluating the Quality of Medical Care. Milbank $Q$. 2005;83(4):691-729.

23. Fierson WM; American Academy of Pediatrics Section on Ophthalmology; American Academy of Ophthalmology; American Association for Pediatric Ophthalmology and Strabismus; American Association of Certified Orthoptists. Screening examination of premature infants for retinopathy of prematurity. Pediatrics. 2013;131(1):189-195.

24. Blencowe H, Lawn JE, Vazquez T, Fielder A, Gilbert C. Preterm-associated visual impairment and estimates of retinopathy of prematurity at regional and global levels for 2010. Pediatr Res. 2013;74 Suppl 1:35-49.

25. Richter GM, Sun G, Lee TC, et al. Speed of Telemedicine versus Ophthalmoscopy for Retinopathy of Prematurity Diagnosis. Am J Ophthalmol. 2009;148(1):136-142.e2.

26. Myung JS, Gelman R, Aaker GD, Radcliffe NM, Chan RV, Chiang MF. Evaluation of Vascular Disease Progression in Retinopathy of Prematurity using Static and Dynamic Retinal Images. Am J Ophthalmol. 2012;153(3):544-551.e2.

27. Richter GM, Williams SL, Starren J, Flynn JT, Chiang MF. Telemedicine for Retinopathy of Prematurity Diagnosis: Evaluation and Challenges. Surv Ophthalmol. 2009;54(6):671-685.

28. Wang SK, Callaway NF, Wallenstein MB, Henderson MT, Leng T, Moshfeghi DM. SUNDROP: six years of screening for retinopathy of prematurity with telemedicine. Can J Ophthalmol. 2015; 50(2):101-106.

29. Lorenz B, Spasovska K, Elflein H, Schneider N. Wide-field digital imaging based telemedicine for screening for acute retinopathy of prematurity (ROP). Six-year results of a multicentre field study. Arch Clin Exp Ophthalmol. 2009;247(9):1251-1262.

30. Website: http://www.who.int/en/. Visual impairment and blindness (Fact Sheet $N^{\circ} 282$ Updated August 2014) available from: http://www. who.int/mediacentre/factsheets/fs282/en/. Accessed on 24/11/2015.

31. Unwin N, Whiting D, Guariguata L, Ghyoot G, Gan D, Eds., Diabetes Atlas, International Diabetes Federation, Brussels, Belgium, 5th edition, 2011.

32. Owsley C, McGwin G Jr, Lee DJ, et al; Innovative Network for Sight (INSIGHT) Research Group. Diabetes eye screening in urban settings serving minority populations: detection of diabetic retinopathy and other ocular findings using telemedicine. JAMA Ophthalmol. 2015; 133(2):174-181.

33. Whited JD. Accuracy and reliability of teleophthalmology for diagnosing diabetic retinopathy and macular edema: a review of the literature. Diabetes Technol Ther. 2006;8(1):102-111.

34. Li Z, Wu C, Olayiwola JN, Hilaire DS, Huang JJ. Telemedicine-based digital retinal imaging vs standard Ophthalmologic evaluation for the assessment of diabetic retinopathy. Conn Med. 2012;76(2):85-90.

35. Ng M, Nathoo N, Rudnisky CJ, Tennant MT. Improving access to eye care: teleophthalmology in Alberta. Canada. J Diabetes Sci Technol. 2009;3(2):289-296.

36. Website: americantelemed.org. Telehealth practice recommendations for Diabetic retinopathy February 2011. Available from: http://www. americantelemed.org/docs/default-source/standards/telehealth-practicerecommendations-for-diabetic-retinopathy.pdf?sfvrsn=10. Accessed $3 / 8 / 2015$. 
37. Silva PS, Cavallerano JD, Aiello LM, Aiello LP. Telemedicine and diabetic retinopathy: moving beyond retinal screening. Arch Ophthalmol. 2011;129(2):236-242.

38. Gómez-Ulla F, Fernandez MI, Gonzalez F, et al. Digital retinal images and teleophthalmology for detecting and grading diabetic retinopathy. Diabetes Care. 2002;25(8):1384-1389.

39. Rubio MM, Moya MM, Bellot Bernabé A, Martínez JB. Diabetic retinopathy screening and teleophthalmology. Arch Soc Esp Oftalmol. 2012;87(12):392-395.

40. Cavallerano AA, Cavallerano JD, Katalinic P, et al; Joslin Vision Network Research Team. A telemedicine program for diabetic retinopathy in a Veterans Affairs Medical Center-the Joslin Vision Network Eye Health Care Model. Am J Ophthalmol. 2005;139(4):597-604.

41. Cuadros J, Bresnick G. EyePACS: An Adaptable Telemedicine System for Diabetic Retinopathy Screening. J Diabetes Sci Technol. 2009;3(3):509-516.

42. Massin P, Chabouis A, Erginay A, et al. OPHDIAT: A telemedical network screening system for diabetic retinopathy in the Île-de-France. Diabetes Metab. 2008;34(3):227-234.

43. Thomas SM, Jeyaraman MM, Hodge WG, et al. The Effectiveness of Teleglaucoma versus In-Patient Examination for Glaucoma Screening: A Systematic Review and Meta-Analysis. PLoS One. 2014;9(12):e113779.

44. Li HK, Tang RA, Oschner K, Koplos C, Grady J, Crump WJ. Telemedicine Screening of Glaucoma. Telemed J. 1999;5(3):283-290.

45. Kassam F, Sogbesan E, Boucher S, et al. Collaborative care and teleglaucoma: a novel approach to delivering glaucoma services in Northern Alberta, Canada. Clin Exp Optom. 2013;96(6):577-580.

46. Tuulonen A, Ohinmaa T, Alanko HI, Hyytinen P, Juutinen A, Toppinen E. The application of teleophthalmology in examining patients with glaucoma: a pilot study. J Glaucoma. 1999;8(6):367-373.

47. Verma S, Arora S, Kassam F, Edwards MC, Damji KF. Northern Alberta remote teleglaucoma program: clinical outcomes and patient disposition. Can J Ophthalmol. 2014;49(2):135-140.

48. de Mul M, de Bont AA, Reus NJ, Lemij HG, Berg M. Improving the quality of eye care with tele-ophthalmology: shared-care glaucoma screening. J Telemed Telecare. 2004;10(6):331-336.

49. Wright HR, Diamond JP. Service innovation in glaucoma management: using a web-based electronic patient record to facilitate virtual specialis supervision of a shared care glaucoma programme. Br J Ophthalmol. 2015;99:313-317.

50. Kanagasingam Y, Bhuiyan A, Abràmoff MD, Smith RT, Goldschmidt L, Wong TY. Progress on retinal image analysis for age related macular degeneration. Prog Retin Eye Res. 2014;38:20-42.

51. De Bats F, Vannier Nitenberg C, Fantino B, Denis P, Kodjikian L. Age-related macular degeneration screening using a nonmydriatic digital color fundus camera and telemedicine. Ophthalmologica. 2014;231(3):172-176.

52. Kelly SP, Wallwork I, Haider D, Qureshi K. Teleophthalmology with optical coherence tomography imaging in community optometry. Evaluation of a quality improvement for macular patients. Clin Ophthalmol. 2011;5:1673-1678.

53. Mair F, Whitten P. Systematic review of studies of patient satisfaction with telemedicine. BMJ. 2000;320(7248):1517-1520.

54. Lee JY, Du YE, Coki O, Flynn JT, Starren J, Chiang MF. Parental perceptions toward digital imaging and telemedicine for retinopathy of prematurity management. Graefes Arch Clin Exp Ophthalmol. 2010;248(1): 141-147.

Clinical Ophthalmology

\section{Publish your work in this journal}

Clinical Ophthalmology is an international, peer-reviewed journal covering all subspecialties within ophthalmology. Key topics include: Optometry; Visual science; Pharmacology and drug therapy in eye diseases; Basic Sciences; Primary and Secondary eye care; Patient Safety and Quality of Care Improvements. This journal is indexed on Submit your manuscript here: http://www.dovepress.com/clinical-ophthalmology-journal
55. Paul PG, Raman R, Rani PK, Deshmukh H, Sharma T. Patient satisfaction levels during teleophthalmology consultation in rural South India. Telemed J E Health. 2006;12(5):571-578.

56. Kumar S, Tay-Kearney ML, Constable IJ, Yogesan K. Internet based ophthalmology service: impact assessment. Br J Ophthalmol. 2005;89(10):1382-1383.

57. Court JH, Austin MW. Virtual glaucoma clinics: patient acceptance and quality of patient education compared to standard clinics. Clin Ophthalmol. 2015;9:745-749.

58. Sreelatha OK, Ramesh SV, Jose J, Devassy M, Srinivasan K. Virtually controlled computerised visual acuity screening in a multilingual Indian population. Rural Remote Health. 2014;14(3):2908.

59. Kurji K, Kiage D, Rudnisky CJ, Damji KF. Improving diabetic retinopathy screening in Africa: patient satisfaction with teleophthalmology versus ophthalmologist-based screening. Middle East Afr J Ophthalmol. 2013;20(1):56-60.

60. Gupta SC, Sinha SK, Dagar AB. Evaluation of the effectiveness of diagnostic \& management decision by teleophthalmology using indigenous equipment in comparison with in-clinic assessment of patients. Indian $J$ Med Res. 2013;138(4):531-535.

61. Johnson KA, Meyer J, Yazar S,Turner AW. Real-time teleophthalmology in rural Western Australia. Aust J Rural Health. 2015;23(3):142-149.

62. Muccioli C, Silva LMP, Finamor LP, et al. Teleophthalmology - The Brazilian Experience and Future Directions. Teleophthalmology 2006, pp 147-153. http://link.springer.com/chapter/10.1007\%2F3-54033714-8_19\# last accessed on 9/8/2015.

63. Ribeiro AG, Rodrigues RA, Guerreiro AM, Regatieri CV. A teleophthalmology system for the diagnosis of ocular urgency in remote areas of Brazil. Arq Bras Oftalmol. 2014;77(4):214-218.

64. John S, Sengupta S, Reddy SJ, Prabhu P, Kirubanandan K, Badrinath SS. The Sankara Nethralaya mobile teleophthalmology model for comprehensive eye care delivery in rural India. Telemed $J$ E Health. 2012;18(5):382-387.

65. Verma M, Raman R, Mohan RE. Application of tele-ophthalmology in remote diagnosis and management of adnexal and orbital diseases. Indian J Ophthalmol. 2009;57(5):381-384.

66. Chen LS, Tsai CY, Liu TY, et al. Feasibility of tele-ophthalmology for screening for eye disease in remote communities. J Telemed Telecare. 2004;10(6):337-341.

67. Dragnev D, Mahmood U, Chris Williams C, Kulshrestha M. Teleophthalmology: Eye Care in the Community (Chapter 1)Website: www.intechopen. com. Available from: http://www.intechopen.com/books/telemedicine/ teleophthalmology-eye-care-in-the-community. Accessed Nov 26, 2015.

68. Kumar S, Yogesan K, Hudson B, Tay-Kearney ML, Constable IJ. Emergency eye care in rural Australia: role of internet. Eye (Lond). 2006; 20(12):1342-1344.

69. Cook C, Murdoch I, Kennedy C, Taylor P, Johnson K, Godoumov R. Teleophthalmology and Vision 2020 in South Africa. S Afr Med J. 2004;94(9):750-751.

70. Chasan JE, Delaune B, Maa AY, Lynch MG. Effect of a teleretinal screening program on eye care use and resources. JAMA Ophthalmol. 2014;132(9):1045-1051.

71. Kumar S, Constable IJ, Yogesan K. Reimbursement for internet based eye care. Br J Ophthalmol. 2005;89(10):1234-1235.

72. Kumar S, Yogesan K. Internet-based eye care: VISION 2020. Lancet. 2005;366(9493):1244-1245.

\section{Dovepress}

PubMed Central and CAS, and is the official journal of The Society of Clinical Ophthalmology (SCO). The manuscript management system is completely online and includes a very quick and fair peer-review system, which is all easy to use. Visit http://www.dovepress.com testimonials.php to read real quotes from published authors. 